\title{
Advancement of oil/water separating materials: merits and demerits in real-time applications
}

\begin{abstract}
With the increase of offshore drilling of oil, production and transportation the chances of oil spillage has enormously increased. Oil spillages have a catastrophic impact on our aquatic environment and ecosystem. In the last few years development of special wettable materials for oil-water separation has received tremendous research and industrial interest. Materials with selective wettability, that is superhydrophobic and superoleophilic, or superhydrophilic and superoleophobic, can be used to remove only one phase from the oil/water mixture. Moreover, the effect of the surface chemistry and surface architecture can further promote the superwetting behaviour and improves separation efficiency. In this review, recently developed materials for oil/water separation are summarized and discussed. These materials have been categorized based on their oil/water separating mechanisms that is filtration or absorption. Representative studies are highlighted, with emphasis on the materials wetting properties that is superhydrophobic/superoleophilic or superoleophobic/ superhydrophilic nature, innovative aspects and their applications. The materials with selective wettability can be used for the treatment of oil spills and industrial oily wastewater treatment on an industrial scale. The challenges and future research directions in this emerging and promising research field are briefly described.
\end{abstract}

Keywords: oil-water separation, super wetting property, superhydrophobic, superoleophilic
Volume I Issue I - 2017

\author{
Atanu Jha, KSS Sarma, Subhendu Ray \\ Chowdhury \\ Bhabha Atomic Research Centre, India
}

Correspondence: Subhendu Ray Chowdhury, Isotope and Radiation Application Division, Bhabha Atomic Research Centre, Trombay, Mumbai-400 085, India,

Email rcsubhendu@gmail.com, rcsubhen@barc.gov.in

Received: February 21, 2017 | Published: March 17, 2017

\section{Introduction}

In the last few years, there are hundreds of large oil spill incidents throughout the world, among them Montara oil spill (Australia), Deep water horizon (Gulf of Mexico), Xingang Port oil spill are the most alarming. In India also Mumbai oil spillage 2010 and Chennai oil spillage 2017 leave severe environmental consequences. Oil spillage is one of the most serious environmental and ecological challenges. ${ }^{1,2}$ Oil contamination from various industries is also causing considerable amount of water pollution. The marine atmosphere and sea water are the most affected due to these incidents, so there is an urgent need of development of material for collection and separation of oil and oily organic pollutant from water sources.

The techniques which are being used to clean up such leakage or spillage are mainly skimming, addition of chemical dispersant, use of filtrating medium and various sorbents. Skimming is the most common method for this purpose, but it is very time consuming, costly and inefficient. Second most widely used method is use of oil dispersant, which separates oil into droplets, but this method adds additional toxic chemical into sea and requires additional separating techniques. ${ }^{3,4}$ Use of filtrating materials and sorbents are the most effective and convenient way to the clean and recollects oil from oil spillage. ${ }^{5,6}$ In the last five years, there is an exponential growth in the research related to materials for oil-water separation. Purposefully constructed and specially designed super wetting surface are found to be helpful for selectively separating oil and water. In particular, special wettable materials with distinct opposite affinities towards oil or water are believed to be the most promising materials for selective oil/water separation. ${ }^{7-9}$ The subject to be covered in the following sections are various separation techniques, materials and scientific basis of those.

Specifically, two kinds of special wettable materials are suitable for oil/water separation, i.e., hydrophobic-oleophilic materials, and hydrophilic-oleophobic materials. Superhydrophobic-superoleophilic materials are actually oil removing materials from the bulk. This particular type of wetting property of material will repel the water phase and absorb oil, thus separating oils from an oil and water mixture. Superhydrophilic-superoleophobic materials are water removing material from the oil-water mixture with the reverse selectivity to the oil absorbing materials. Various metallic mesh material, fabric material, carbon based material, powder material, sponge or foam material are reported till date which can be used as oil water separation, ${ }^{10-19}$ but one major drawback of these fabric and mesh materials is that, they cannot be used directly in the sea, oily water has to be collected and then it has to be filtered. These are difficult to scale-up in large scale. ${ }^{20}$ Most effective sorbent reported are the sponge and foam based material because of their easy availability, low cost, very low weight to volume ratio and extremely high porosity they can absorb oil up to hundred times of their weight, but they have less selectivity towards oil or water, they absorb both almost equally. Purposefully constructed and specially designed super wetting surface are found to be helpful for selectively separating oil and water. Drop coating, solution coating, fabrication by electro-spinning, plasma treatment, incorporation of nano particle into sponge material etc. various methodology have been used to prepare such sponges. ${ }^{21-23}$ But this methods require toxic chemicals, involve high cost, less scalability in large scale and low reusability. The main emphasis is given into the specialty of the materials, surface wet ability and merits and demerits. Finally, we provide our conclusions and outlook on the future of the work.

\section{Separation of layered oil-and-water mixtures}

Filtration based separation: Depending upon the wettability, modified filtrating materials like metallic meshes, textiles/fabrics, polyme- 
ric membranes, allow only one particular phase to pass through. These materials are extensively studied in the last few years for oil-water separation.

Metallic mesh-based materials: Superhydrophobicity of metallic meshes has been studied over the past few years. ${ }^{11,24-26}$ To enhance the selective permeability to water and oil, filtering mesh with superhydrophobic and superoleophilic behaviour is prepared, resulting in oil/water separating properties. Feng et al. ${ }^{27}$ has reported the first super-hydrophobic and superoleophilic stainless steel mesh prepared via a spray and-dry method in 2004. ${ }^{27}$ The surface morphology of the mesh is rough and because of its superhydrophobicity and superoleophilicity, water droplet stays as a spherical bead on the mesh and oil (diesel) droplet passes through it (Figure 1). In addition to stainless steel mesh, copper mesh is one of the another frequently used substrates for oil/water separation..$^{28-33}$ Wang et al. ${ }^{30}$ reported a superhydrophobic and superoleophilic copper mesh, This as prepared mesh could be used to separate a mixture of oil and water. Similarly, superhydrophilic and superoleophobic meshes can also be used for the same purpose. Preparation of these kinds of material which show both hydrophilicity and oleophobicity is difficult as surface energy of water is higher than oil. ${ }^{9}$ Yang et al. ${ }^{34}$ reported a polymer based superhydrophilic and superoleophobic coating material, prepared from hydrophilic poly (di-allyl di-methyl ammonium chloride) (PDDA) and oleophobic sodium perfluroocanoate $(\mathrm{PFO})$ and $\mathrm{SiO}_{2}$ nanoparticles. It allows water to spread through the mesh and oil drop keeps minimum contact with the surface and stays as a spherical bead (Figure 2). Kota et al. reported hygro-responsive superhydrophilic and superoleophobic membrane material by dip-coating method. ${ }^{35}$ Most of the oil are of less density than water, so a filtrating material with superhydrophilicity and oleophobicity will be more useful and feasible for oil-water separation, if the oil-water mixture is a layered (immiscible) system. Mesh material with underwater superoleophobic superhydrophilic surface can be designed by appropriate surface energy and surface roughness. ${ }^{36,37}$ These materials are also applicable to oil-water separation. Xue et al. ${ }^{36}$ reported polyacrylamide-hydrogel coated mesh with underwater superoleophobicity. These type of materials overcome the disadvantage of fouling due to oil absorbance which was a major issue with superhydrophobic-oleophilic materials.

Fabric/textile based materials: Apart from inorganic porous metal films, soft and flexible organic fabric materials have also been found as a good candidate for oil/water separation. Zhang et al. ${ }^{38}$ reported a superhydrophobic cotton textile with oil/water separating properties by dip coating method. Tang et al. ${ }^{39}$ and Shang et al. ${ }^{40}$ fabricated a superhydrophobic and superoleophilic nanofibrous membrane with oil/water separation properties using a combination of electrospun poly(m-phenyleneisophthalamide) (PMIA) nanofibers and a novel in situ polymerized fluorinated polybenzoxazine (F-PBZ) functional layer that incorporated $\mathrm{SiO}_{2}$ NPs. Zhang et al. ${ }^{41}$ proposed a superhydrophobic and superoleophilic polyester textile using a one-step growth of silicone nanofilaments onto the textile via chemical vapour deposition method. Zhang et al. ${ }^{42-44}$ reported couple of durable and robust superhydrophobic textiles with good mechanical, chemical and environmental stability. Oil-water mixture can be separated by using very simple experimental set up using these textile materials (Figure 3). Few materials have been reported which show responsive wettability. Xu et al..$^{45}$ reported ammonia responsive superhydrophilic and superoleophobic polyester textile material. Xiong et al ${ }^{46}$ reported a unique simple textile material for switchable wettability by using $\mathrm{ZnO}$ nanorod deposited polyethylene terepthalate, which displays un- derwater oleophobicity and under oil hydrophobicity. The developed fabrics, prepared using various physical and chemical routes, has been found to be useful for separating oil-water mixture. But the major drawback of these materials is that the contaminated water has to be collected first and then can be separated, we can not use these filtering materials directly in real sites. ${ }^{9}$

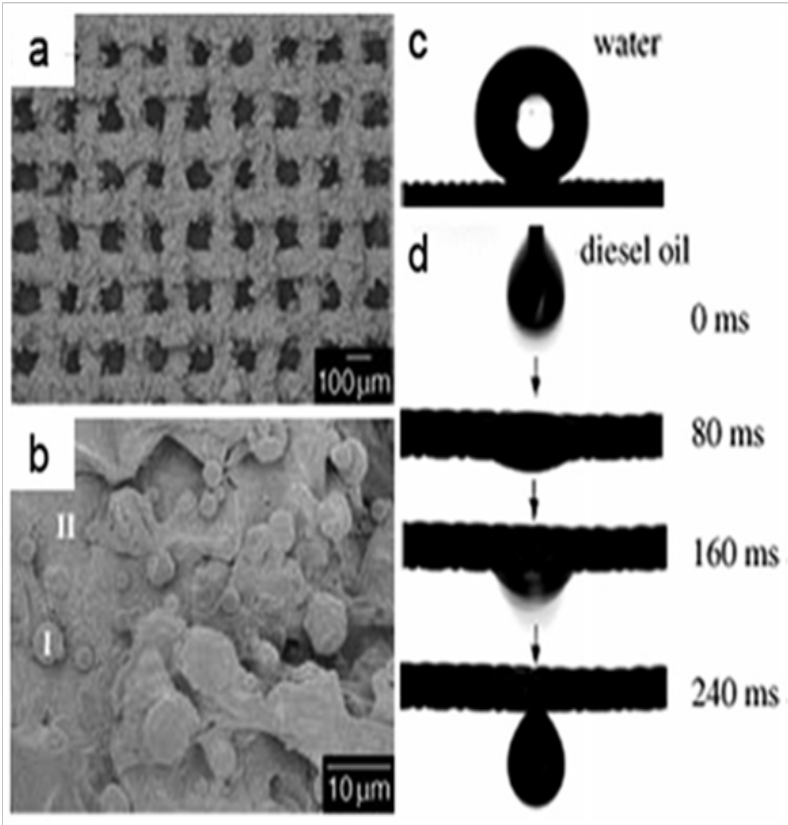

Figure I: (A) Scanning electron microscopy (SEM) images of the stainless steel mesh coating; (B) high resolution view of (A). (C) The shape of a water droplet on the resulting mesh film with a water contact angle (WCA) of $156.2^{\circ} \pm 2.8^{\circ}$; (D) the diesel oil spreads and penetrates the copper mesh film quickly within only $240 \mathrm{~ms}$, indicating an oil contact angle (OCA) of $1.4^{\circ} .{ }^{27}$

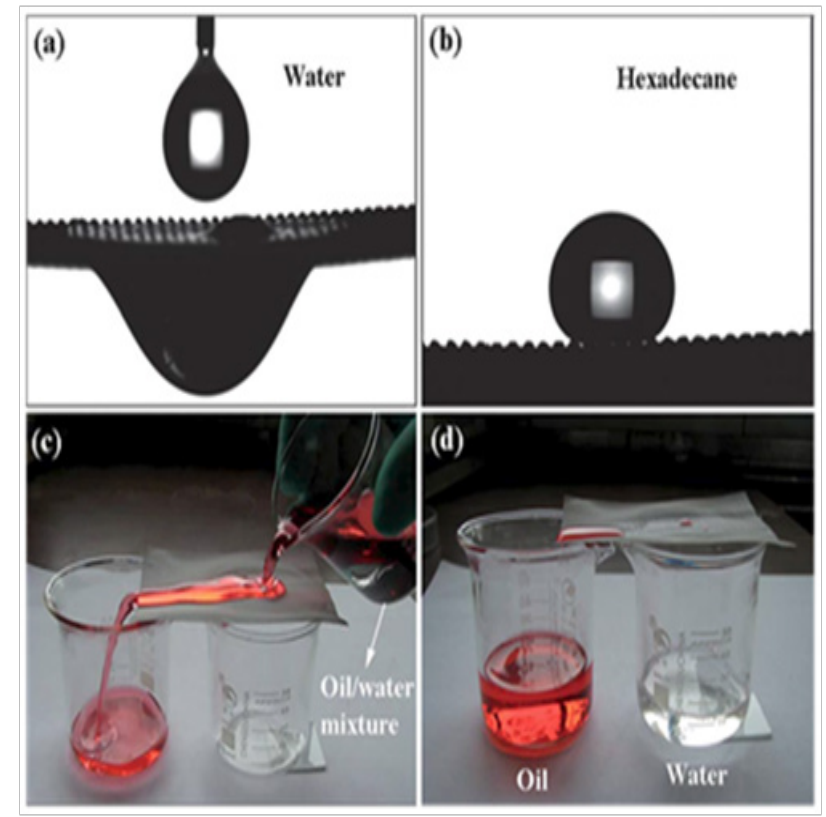

Figure 2: The PDDA-PFO/SiO ${ }_{2}$-coated mesh film shows special wettability, with both superhydrophilic and superoleophobic properties. (A)Water droplet spreading on and permeating through the mesh. (B) Shape of a hexadecane droplet on the mesh with a contact angle of $157^{\circ} \pm 2^{\circ}$. (c and d) Oil/water separation experiment was performed on the PDDA-PFO/SiO ${ }_{2}$-coated mesh. ${ }^{34}$ 


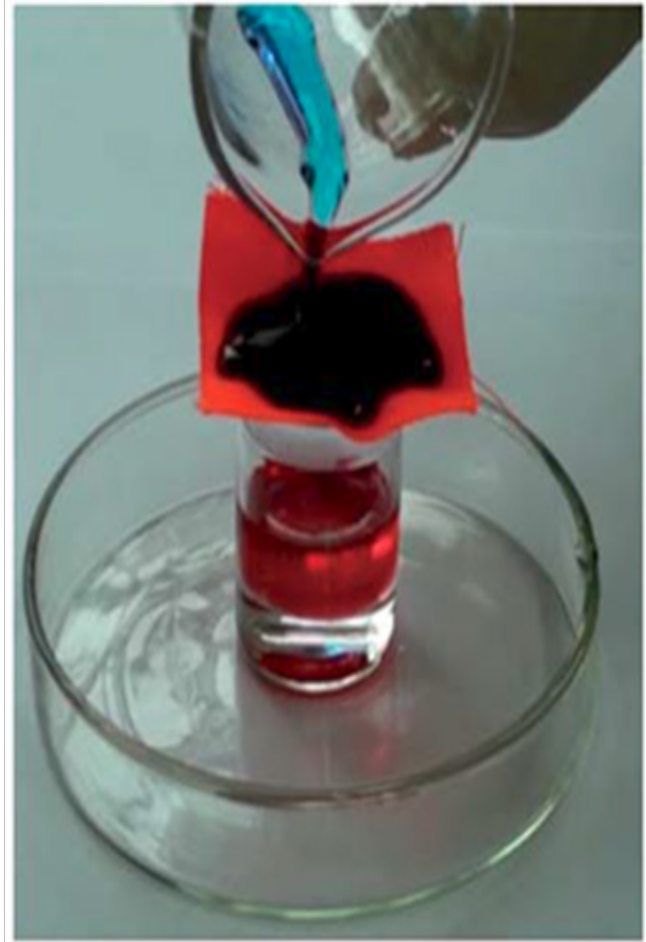

Figure 3: Simple experimental setup for oil/water separation using modified textile material. Oil is colored with Or range red and water is colored with Methyl blue. ${ }^{43}$

\section{Absorption based separation}

Although various advanced filtration materials with special and tunable wetting properties have been developed for selective oil/water separation, they still have difficulties for the in-situ application. In the last couple of years, much research effort has been devoted to developing advanced absorbents with special wetting properties that can selectively separate oil-water mixture.

Particle and Powdered Absorbents: Powdered materials, such as activated carbons and zeolites, iron nano particles etc. have been studied by various research groups. Arbatan et al ${ }^{47}$ reported a superhydrophobic and oleophilic calcium carbonate powder that can separate oil from an oil water mixture quickly. ${ }^{47}$ Hydrophobic polymer coated silica particles has been reported to be useful for petroleum hydrocarbon removal by Akhavan et al. ${ }^{48}$ Recently developed few metal organic frameworks (MOF) with special wettability are also found to be very promising in this regard. ${ }^{49-51}$ Yong et al ${ }^{52}$ very recently reported an underwater superoleophobic pre wetted sand material for oil-water separation. However, these traditional powered absorbents very difficult to handle, especially during the re-collection process. Magnetic particles/powders were developed to overcome the recycling problem because particles/powders with magnetism can be easily collected using an external magnetic field. ${ }^{53}$ Though the materials are found to be useful in oil-water separation, its low absorption capacity and less stability in harsh environment hinder its wider acceptance. ${ }^{9}$

Sponge based materials: Sponge and foam based materials have gained considerable interest in this aspect because of its inherent properties like easy availability, low cost, porous, high absorbance capacity, with initial wettable properties. Usually, they can absorb various liquids (including water and oils or organics), which make them unrealistic for removing oils/organics from the water phase because of their poor selectivity. High selectivity has been introduced onto these materials by purposeful construction of befitting surface topography and modification by functional molecules with special wetting property. Different promising routes such as in situ growth, ${ }^{54}$ dip coating, ${ }^{55}$ polymerized octadecylsiloxane coating, ${ }^{56}$ carbon nanotube/poly(dimethylsiloxane) based coating, ${ }^{23}$ block copolymer (BCP) grafting, ${ }^{57}$ solution-immersion, ${ }^{58}$ sugar templating, ${ }^{59}$ vapour phase polymerization ${ }^{60}$ for developing special wettability of these materials have been followed by various research groups. Coating of various low surface energy molecule on the surface of sponge based materials are widely used means for attaining superhydrophobiciy and superoleophilicity. ${ }^{23,58,61-63}$ Shuai et al ${ }^{64}$ reported polydimethylsiloxane $-\mathrm{TiO}_{2}$ coated superdydrophobic polyurethane (PU) sponge. Various carbon based materials like CNT, grapheme, etc have been applied as a hydrophobic coating /modifying agent. ${ }^{65-67}$ One disadvantage associated with most polymeric sponges is their instability. These materials cannot withstand the situation related to site applications, such as bending, twisting, pressing etc. Few groups have reported superhydrophobic-superoleophilic melamine based sponge material with extensive temperature and fire resistance. ${ }^{68,69}$ Our group has recently introduced a rapid, single step, scalable, economic and sustainable route to incorporate super selectivity towards oily liquid to the sponge upon modification via gamma radiation assisted grafting of a low surface energy molecule (dodecyl 2-methacrylate).$^{70}$ In a oilwater mixture it absorbs only oil and cleans the water, the absorbed oil can be easily recollected by squeezing (Figure $4 \&$ Figure 5 ). This is the first material which can separate oil/water from both layered and emulsion oil/water mixtures. Wang et al..$^{71}$ reported a cellulose sponge with robust superhydrophilicity and under-water superoleophobicity for highly effective oil/water separation. Smart surfaces are able to switch between superoleophilicity to superoleophobicity in presence of water on any other stimuli like $\mathrm{pH}$ or temperature. Zhang et al. ${ }^{57}$ used a $\mathrm{pH}$ responsive poly (2-vinylpyridine) (PVP) and oleophilic hydrophobic polydimethylsiloxane (PDMS) as coating materials onto sponge surfaces for $\mathrm{pH}$ responsive wettability. ${ }^{57}$ Recently few innovative strategies has been developed for continuous separation of oil-water which out ways the absorbance capacity of some materials. ${ }^{72}$ Ge et al. ${ }^{73}$ designed a pump with the sponge for absorbent-pumping system (Figure 6).

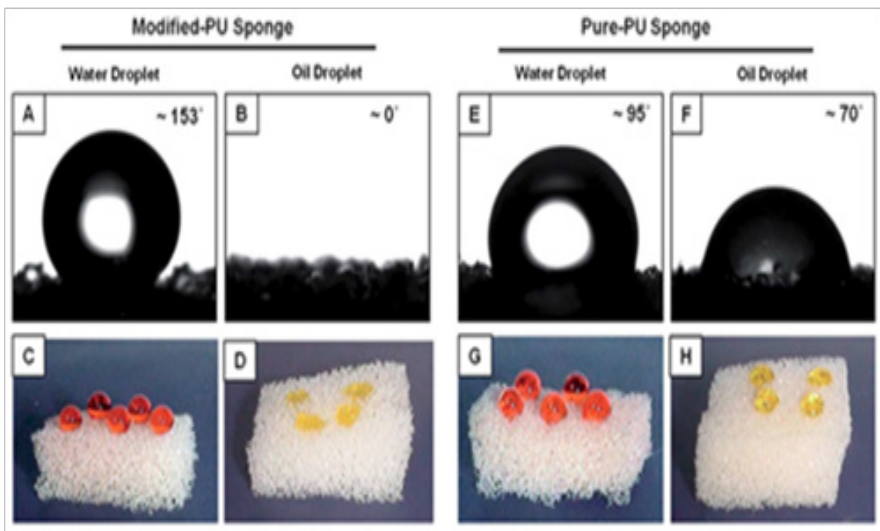

Figure 4: $(A-H)$ Images of contact angles (A \& B, E \& F) and beading (C \& D, G \& $H$ ) of liquid water $(A, C, E)$ and $(G)$ and oil $(B, D, F$ and $H)$ droplets on both the pure-PU sponge $(\mathrm{E}-\mathrm{H})$ and DMA-grafted $\mathrm{PU}$ sponge (A-D). ${ }^{70}$ 


\section{Oil-Water Separation by Modified PU}
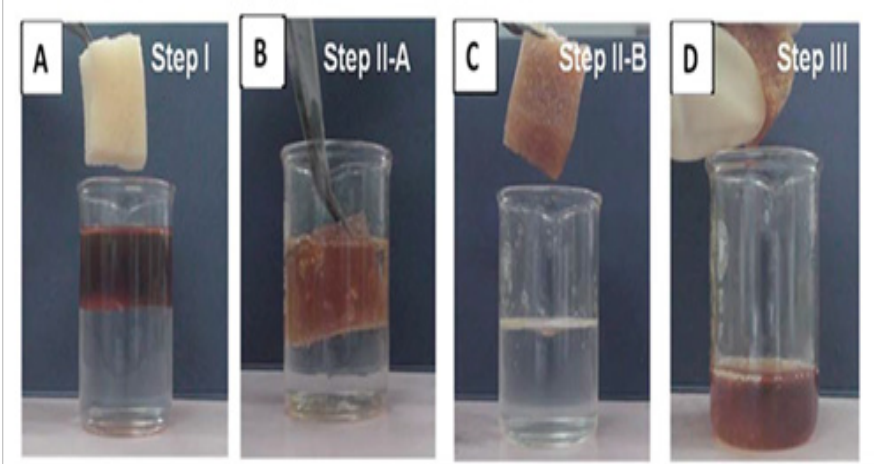

Figure 5: (A-D) Oil/water separation and recollection of oil from the modified sponge by mechanical squeezing. ${ }^{70}$

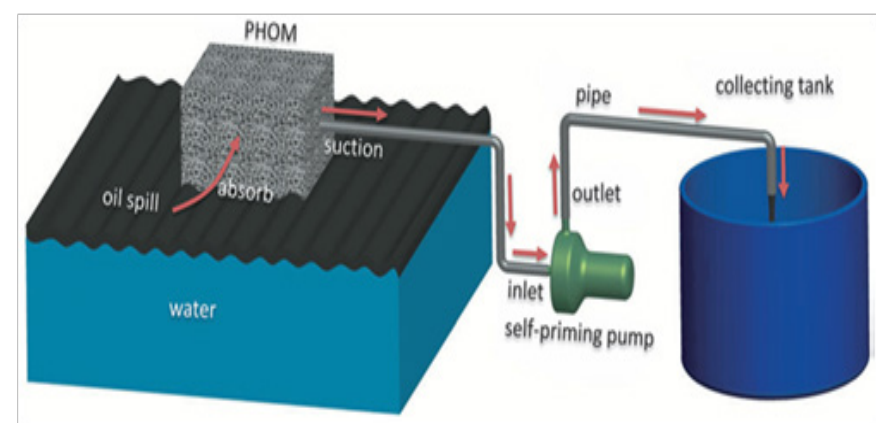

Figure 6: Diagrammatic representation of sponge based absorbent-pumping system for continuous oil-water separation. The oil on the water surface is selectively absorbed by the sorbent and flows along the pipe into the collecting vessel until all oil is consumed. ${ }^{73}$

\section{Conclusion}

In this article, we have reviewed recently developed various novel materials based on both filtration and absorption methods. The required wetting properties include hydrophobicity and oleophilicity, hydrophilicity and oleophobicity, superhydrophilicity and underwater superoleophobicity, and responsive/ switchable wettability. Although oil/water separation with special wettable materials is a rapidly growing and promising research field, there are still some challenges to overcome. There is still a lack of understanding of the basic mechanisms of interactions between oil and the surface of the materials used to clean up the oil. Fundamental theories and models are required in order to guide further development of novel materials. Among the reported works, for many of the cases the synthesis methods cannot be performed on large-scale (such as the in situ growth method and hydrothermal method) and thus the mass-production techniques of oil/water separation materials for the large-area oil spills need to be developed. Very few reported works have addressed the separation of oil-water emulsions. Effective and high-throughput separation of a wide range of oil/water emulsions with a range of droplet sizes from the micrometer to the nanometer range is an important issue and need more research interest. In most of the cases the studies have been performed using low-viscous oil, however, research on the separation of high-viscous oil-and-water mixtures are rare. Thus future research is required to be carried out to overcome the aforementioned challenges. We believe this mini-review could generate more research interest in this blooming area.

\section{Acknowledgements}

None.

\section{Conflict of interest}

The author declares no conflict of interest.

\section{References}

1. Short JW. Long-term effects of crude oil on developing fish: lessons from the Exxon Valdez oil spill. Energy Sources. 2003;25(6):509-517.

2. Dubansky B, Whitehead A, Miller JT, et al. Multitissue molecular, genomic, and developmental effects of the deepwater horizon oil spill on resident gulf killifish (Fundulus grandis). Environ Sci Technol. 2003;47(10):5074-5082.

3. Broje V, Keller AA. Improved mechanical oil spill recovery using an optimized geometry for the skimmer surface. Environ Sci Technol. 2006;40(24):7914-7918.

4. Kujawinski EB, Kido Soule EB, ValentineDL, et al. Fate of dispersants associated with the deepwater horizon oil spill. Environ Sci Technol. 2011;45(4):1298-1306.

5. Choi HM and Cloud RM. Natural sorbents in oil spill cleanup. Environ Sci Technol. 1992;26(4):772-776.

6. Adebajo MO, Frost RL, Kloprogge JT, et al. Porous materials for oil spill cleanup: a review of synthesis and absorbing properties. Journal of Porous Materials. 2003;10(3):159-170.

7. Chu Z, Feng Y, Seeger S. Oil/water separation with selective superantiwetting/superwetting surface materials. Angewandte Chemie International Edition. 2014;54(8):2328-2338.

8. Xue ZX, Cao YZ, Liu N, et al. Special wettable materials for oil/water separation. J Mater Chem A. 2014;2(8):2445-2460.

9. Wang B, Liang W, Guo Z, et al. Biomimetic superlyophobic and super-lyophilic materials applied for oil/water separation: a new strategy beyond nature. Chem Soc Rev. 2015;44(1):336-361.

10. Zhou H, Wang HX, Niu HT, et al. Robust, Self-healing superamphiphobic fabrics prepared by two-step coating of fluoro-containing polymer, fluoroalkyl silane, and modified silica nanoparticles. Advanced Functional Materials. 2013;23(13):1664-1670.

11. Guo ZG, Zhou F, Hao JC, et al. Stable biomimetic superhydrophobic engineering materials. J Am Chem Soc. 2005;127(45):15670-15671.

12. Feng L, Zhang Z, Mai Z, et al. A super-hydrophobic and super-oleophilic coating mesh film for the separation of oil and water. GDCh; 2004;116(15):2046-2048.

13. Tuteja A, Choi W, Ma M, et al. Designing superoleophobic surfaces. Science. 2007;318(5856):1618-1622.

14. Singh E, Chen Z, Houshmand F, et al. Superhydrophobic graphene foams. Small. 20123;9(1):75-80.

15. Dong X, Chen J, Ma Y, et al. Superhydrophobic and superoleophilic hybrid foam of graphene and carbon nanotube for selective removal of oils or organic solvents from the surface of water. Chem Commun (Camb). 2012;48(86):10660-10662.

16. Cho YK, Park EJ, Kim YD. Removal of oil by gelation using hydrophobic silica nanoparticles. J Ind Eng chem. 2013;20(4):1231-1235.

17. Wang XS, Liu J, Bonefont JM, et al. A porous covalent porphyrin framework with exceptional uptake capacity of saturated hydrocarbons for oil spill cleanup. Chem Commun (Camb). 2013;49(15):1533-1535. 
18. Zhang XY, Li Z, Liu KS, et al. Bioinspired multifunctional foam with self-cleaning and oil/water separation. Advanced Functional Materials 2013;23(22):2881-2886

19. Wang Y, Shi Y, Pan L, et al. Multifunctional superhydrophobic surfaces templated from innately microstructured hydrogel matrix. Nano Lett. 2014;14(8):4803-4809.

20. Wang B, Liang W, Guo Z, et al. Biomimetic superlyophobic and super-lyophilic materials applied for oil/water separation: a new strategy beyond nature. Chem Soc Rev. 2015;44(1):336-361.

21. Zhu Q, Pan Q. Mussel-inspired direct immobilization of nanoparticles and application for oil water separation. ACS Nano. 2014;8(2):14021408

22. Jiang L, Zhao Y, Zhai J. A Lotus-leaf-like superhydrophobic surface: a porous microsphere/nanofiber composite film prepared by electrohydrodynamics. Angew Chem Int Ed Engl. 2004;43(33):4338-4441.

23. Wang CF, Lin SJ. Robust superhydrophobic/superoleophilic sponge for effective continuous absorption and expulsion of oil pollutants from water. ACS Appl Mater Interfaces. 2013;5(18):8861-8864.

24. Guo ZG, Liu WM, Su BL. A stable lotus-leaf-like water-repellent copper. Applied Physics Letters. 2008;92(6):63104-63107.

25. Song JL, Huang S, Hu K, et al. Fabrication of superoleophobic surfaces on Al substrates. J Mater Chem A. 2013;1(46):14783-14789.

26. Sethi S, Dhinojwala A. Superhydrophobic conductive carbon nanotube coatings for steel. Langmuir. 2009;25(8):4311-4313.

27. Feng L, Zhang Z, Mai Z, et al. A super-hydrophobic and super-oleophilic coating mesh film for the separation of oil and water. Angew Chem Int Ed Engl. 2004;43(15):2012-2014.

28. Wang ST, Song YL, Jiang L. Microscale and nanoscale hierarchical structured mesh films with superhydrophobic and superoleophilic properties induced by long-chain fatty acids. Nanotechnology. 2007;18(1):015103.

29. Wang B, Guo ZG. Superhydrophobic copper mesh films with rapid oil/ water separation properties by electrochemical deposition inspired from butterfly wing. Appl Phys Lett. 2013;103(6):063704.

30. Wang C, Yao T, Wu J, et al. Facile Approach in Fabricating Superhydrophobic and Superoleophilic Surface for Water and Oil Mixture Separation. ACS Appl Mater Interfaces. 2009;11(1):2613-2617.

31. Gao CR, Sun ZX, Li K, et al. Durable superhydrophobic/superoleophilic PDMS sponges and their applications in selective oil absorption and in plugging oil leakages. Energy Environ Sci. 2013;6(43):1147-1151.

32. Yang Y1, Li H, Cheng S, et al. Robust diamond meshes with unique wettability properties. Chem Commun (Camb). 2014;50(22):2900-2903.

33. Crick CR, Gibbins JA, Parkin IP. Superhydrophobic polymer-coated copper-mesh; membranes for highly efficient oil-water separation. $J$ Mater Chem A. 2013;1(19):5943-5948.

34. Yang J, Zhang ZZ, Xu XH, et al. Superhydrophilic-superoleophobic coatings. J Mater Chem. 2012;22(7):2834-2837.

35. Kota AK, Kwon G, Choi W, et al. Hygro-responsive membranes for effective oil-water separation. Nat Commun. 2012;3:1025-1033.

36. Xue Z, Wang S, Lin L, et al. A Novel Superhydrophilic and underwater superoleophobic hydrogel-coated mesh for oil/water separation. $A d v$ Mater. 2012;23(37):4270-4273.

37. Zhang L, Zhong Y, Cha D, et al. A self-cleaning underwater superoleophobic mesh for oil-water separation. Scientific Reports. 2013;3:2326
38. Zhang M, Wang C, Wang S, et al. Fabrication of superhydrophobic cotton textiles for water-oil separation based on dip-coating route. Carbohydr Polym. 2013;197(1):59-64.

39. Tang X, Si Y, Ge J, et al. In situ polymerized superhydrophobic and superoleophilic nanofibrous membranes for gravity driven oil-water separation. Nanoscale. 2013;5(23):11657-11664

40. Shang Y, Si Y, Raza A, et al. An in situ polymerization approach for the synthesis of superhydrophobic and superoleophilic nanofibrous membranes for oil-water separation. Nanoscale. 2012;4(24):7847-7854.

41. Zhang JP, Seeger S. Polyester materials with superwetting silicone nanofilaments for oil/water separation and selective oil absorption. Advanced Functional Materials. 2011;21(24):4699-4704.

42. Zhang J, Li B, Wu L, et al. Facile preparation of durable and robust superhydrophobic textiles by dip coating in nanocomposite solution of organosilanes. Chem Commun (Camb). 2013;49(98):11509-11511.

43. Wu L, Zhan JP, Li BC, et al. Mimic nature, beyond nature: facile synthesis of durable superhydrophobic textiles using organosilanes. $J \mathrm{Ma}$ ter Chem B. 2013;1(37):4756-4763.

44. Wu L, Zhan JP, Li BC, et al. Magnetically driven super durable superhydrophobic polyester materials for oil/water separation. Polym Chem. 2014;5(7):2382-2390.

45. Xu Z, Zhao Y, Wang $\mathrm{H}$, et al. A superamphiphobic coating with an ammonia-triggered transition to superhydrophilic and superoleophobic for oil-water separation. Angew Chem Int Ed Engl. 2015;54(15):45274530

46. Xiong S, Kong L, Huang J, et al. Atomic-layer-deposition-enabled nonwoven membranes with hierarchical $\mathrm{ZnO}$ nanostructures for switchable water/oil separations. J Membrane Sci. 2015;493(1):478-485.

47. Arbatan T, Fang XY, Shen W. Superhydrophobic and oleophilic calcium carbonate powder as a selective oil sorbent with potential use in oil spill clean-ups. Chemical Engineering Journal. 2011;166(2):787-791.

48. Akhavan B, Jarvis K, Majewski P. Hydrophobic plasma polymer coated silica particles for petroleum hydrocarbon removal. ACS Appl Mater Interfaces. 2013;5(17):8563-8571.

49. Barea E, Montoro C, Navarro JAR. Toxic gas removal--metal-organic frameworks for the capture and degradation of toxic gases and vapours. Chem Soc Rev. 2014;43(16):5419-5430.

50. Qiu S, Xue M, Zhu G. Metal organic framework membranes: from synthesis to separation application. Chem Soc Rev. 2014;43(16):61166140

51. Zhu QL, Xu Q. Metal-organic framework composites. Chem Soc Rev. 2014;43(16):5468-5512.

52. Yong J, Chen F, Yang Q, et al. Oil water separation: a gift from the desert. Advanced materials interfaces. 2016;3(7):1500650-1500657.

53. Xu LP, Wu X, Meng J, et al. Papilla-like magnetic particles with hierarchical structure for oil removal from water. Chem Commun (Camb). 2013;49(78):8752-8754.

54. Wang B, Li J, Wang G, et al. Methodology for robust superhydrophobic fabrics and sponges from in situ growth of transition metal/metal oxide nanocrystals with thiol modification and their applications in oil/water separation. ACS Appl Mater Interfaces. 2013;5(5):1827-1839.

55. Wu J, Wang N, Wang L, et al. Electrospun porous structure fibrous film with high oil adsorption capacity. ACS Appl Mater Interfaces. 2012;4(6):3207-3212

56. Ke Q, Jin Y, Jiang P, et al. Oil/water separation performances of superhydrophobic and superoleophilic sponges. Langmuir. 2014;30(44):1313713142 . 
57. Zhang LB, Zhang ZH, Wang P. Smart surfaces with switchable superoleophilicity and superoleophobicity in aqueous media: toward controllable oil/water separation. NPG Asia Materials. 2012;4:1-8.

58. Zhu Q, Pan QM, Liu FT. Facile Removal and Collection of Oils from Water Surfaces through Superhydrophobic and Superoleophilic Sponges. J Phys Chem C. 2011;115(35):17464-17470.

59. Choi SJ, Kwon TH, Im H, et al. A polydimethylsiloxane (PDMS) sponge for the selective absorption of oil from water. ACS Appl Mater Interfaces. 2011;3(12):4552-4556.

60. Zhou XY, Zhang ZZ, Xu XH, et al. Facile fabrication of superhydrophobic sponge with selective absorption and collection of oil from water. Ind Eng Chem Res. 2013;52(27):9411-9416.

61. Chen N, Pan Q. Versatile fabrication of ultralight magnetic foams and application for oil-water separation. ACS Nano. 2013;7(8):6875-6883.

62. Calcagnile P, Fragouli D, Bayer IS, et al. Magnetically driven floating foams for the removal of oil contaminants from water. ACS Nano. 2012;6(6):5413-5419.

63. Ge B, Zhu XT, Li Y, et al. Versatile fabrication of magnetic superhydrophobic foams and application for oil-water separation. Colloid Surface A. 2015;482(1):687-692.

64. Shuai Q, Yang XT, Luo YM, et al. A superhydrophobic poly(dimethylsiloxane)- $\mathrm{TiO}_{2}$ coated polyurethane sponge for selective absorption of oil from water. Materials Chemistry and Physics. 2015;162(1):94-99.

65. Liu Y, Ma J, Wu T, et al. Cost-effective reduced graphene oxide-coated polyurethane sponge as a highly efficient and reusable oil-absorbent. ACS Appl Mater Interfaces. 2013;5(20):10018-10026.
66. Keshavarz A, Zilouei H, Abdolmaleki A, et al. Enhancing oil removal from water by immobilizing multi-wall carbon nanotubes on the surface of polyurethane foam. J Environ Manage. 2015;157(1):279-286.

67. Xi PX, Huang L, Xu ZH, et al. Low cost and robust soot dipped polyurethane sponge for highly efficient and recyclable oil and organic solvent cleanup. RSC Adv. 2014;4(103):59481-59485.

68. Ruan C, Ai K, Li X, et al. A superhydrophobic sponge with excellent absorbency and flame retardancy. Angew Chem Int Ed. 2014;53(22):55565560 .

69. Pham VH, Dickerson JH. Superhydrophobic silanized melamine sponges as high efficiency oil absorbent materials. ACS Appl Mater Interfaces. 2014;6(16):14181-14188.

70. Ray Chowdhury S, Jha A, Manna U, et al. Designing a single superabsorbent for separating oil from both layered as well as micron/submicron size emulsified oil/water mixtures by gamma radiation assisted grafting. RSC Adv. 2016;6(31):26086-26095.

71. Wang G, He Y, Wang H, et al. A cellulose sponge with robust superhydrophilicity and under-water superoleophobicity for highly effective oil/water separation. Green Chem. 2015;17(5):3093-3099.

72. Ma Q, Cheng H, Fane AG, et al. Recent Development of Advanced Materials with Special Wettability for Selective Oil/Water Separation. Small. 2016;12(16):2186-2202.

73. Ge J, Ye YD, Yao HB, et al. Pumping through porous hydrophobic/ oleophilic materials: an alternative technology for oil spill remediation. Angew Chem Int Ed. 2014;53(14):3612-3616. 